\title{
Peran Mata Kuliah Pendidikan Pancasila secara Daring Terhadap Perilaku Positif Mahasiswa Polbangtan Yogyakarta
}

\author{
Rukha Heny Pramubinasih ${ }^{1}$, Tiara Puspita Arumningtyas ${ }^{2}$ \\ Politeknik Pembangunan Pertanian \\ rukha.heny@gmail.com ${ }^{1}$, tiaramn.tss@gmail.com²
}

\begin{abstract}
ABSTRAK
Pancasila adalah salah satu elemen terpenting negara Indonesia karena Pancasila merupakan pondasi utama atas berdirinya negara Indonesia secara kokoh. Dalam dunia pendidikan, Pancasila merupakan filsafat pendidikan di Indonesia dalam mencapai tujuan bangsa Indonesia untuk mencerdaskan kehidupan bangsa dan menjadi pedoman dalam pelaksanaan pendidikan di Indonesia agar sesuai dengan nilai - nilai luhur. Oleh karena itu, diberlakukanlah mata kuliah pendidikan Pancasila di perguruan tinggi. Namun, berlakunya pendidikan Pancasila di perguruan tinggi mengalami pasang surut dan dalam penyelenggaraannya tidak serta merta diimplementasikan dengan baik. Hal tersebut disebabkan oleh beberapa faktor, seperti perubahan dasar hukum yang mengatur berlakunya pendidikan Pancasila di perguruan tinggi dan persepsi pengembang kurikulum di masingmasing perguruan tinggi yang terus berganti. Pasal 35 ayat (5) Undang - Undang Nomor 12 Tahun 2012 tentang Pendidikan Tinggi menyatakan bahwa kurikulum pendidikan tinggi wajib memuat mata kuliah agama, Pancasila, Kewarganegaraan, dan bahasa Indonesia. Hal tersebut menunjukkan bahwa negara berkehendak agar pendidikan Pancasila dilaksanakan dan wajib dimuat dalam kurikulum perguruan tinggi sebagai mata kuliah yang berdiri sendiri. Metode penelitian ini adalah deskriptif kuantitatif menggunakan sample purposive dengan teknik sampling proportional stratified random sampling. Rumusan masalah penelitian ini adalah bagaimana peran mata kuliah pendidikan Pancasila terhadap perilaku positif mahasiswa Polbangtan Yogyakarta. Tujuan penelitian ini yaitu untuk mengetahui seberapa berperan mata kuliah pendidikan Pancasila yang dilaksanakan secara daring sehingga mampu menciptakan mahasiswa yang berperilaku positif dalam kehidupan sehari-hari baik di lingkungan keluarga, kampus, ataupun masyarakat. Dari hasil analisis disimpulkan bahwa mata kuliah pendidikan Pancasila yang dilaksanakan secara daring di Polbangtan Yogyakarta sudah terlaksana dengan baik sehingga mahasiswa mampu memahami makna Pancasila.
\end{abstract}

Kata Kunci : Pancasila, Pendidikan Pancasila, Peran Pendidikan Pancasila.

\begin{abstract}
Pancasila is one of the most important elements of the Indonesian state because Pancasila is the main foundation for the solid establishment of the Indonesian state. In the world of education, Pancasila is an educational philosophy in Indonesia in achieving the goal of the Indonesian nation to educate the nation's life and serve as a guide in the implementation of education in Indonesia so that it is in accordance with noble values. Therefore, the Pancasila education course in higher education is enforced. However, the implementation of Pancasila education in tertiary institutions has experienced ups and downs and in its implementation it is not automatically implemented properly. This is caused by several factors, such as changes in the legal basis governing the implementation of Pancasila education in tertiary institutions and the changing perceptions of curriculum developers in each university. Article 35 paragraph (5) of Law Number 12 of 2012 states that the higher education curriculum must contain subjects on religion, Pancasila, Citizenship, and Indonesian. This shows that the state wishes that Pancasila education be implemented and must be included in the higher education
\end{abstract}


curriculum as an independent subject. This research method is quantitative descriptive using purposive sampling technique with proportional stratified random sampling technique. The formulation of the research problem is how the role of Pancasila education courses on the positive behavior of Yogyakarta Polbangtan students. The purpose of this research is to find out how much role the Pancasila education courses are implemented online so as to create students who behave positively in everyday life whether in the family, campus, or community environment. From the results of the analysis, it was concluded that the Pancasila education course which was carried out online at Polbangtan Yogyakarta had been carried out well so that students were able to understand the meaning of Pancasila.

Keywords: Pancasila, Pancasila Education, the role of Pancasila Education.

\section{PENDAHULUAN}

Di era globalisasi ini, teknologi dan komunikasi berkembang sangat pesat terkhusus media elektronik yang mampu memengaruhi sikap dan perilaku generasi muda yang tidak sejalan dengan kepribadian bangsa Indonesia. Ditambah saat ini, pandemi Covid-19 sedang mewabah di Indonesia membuat pembelajaran dilaksanakan secara daring. Oleh karena itu, generasi muda yang sedang menempuh pendidikan setiap harinya tidak terlepas dari gadget. Perubahan sikap dan perilaku yang tercermin di kalangan mahasiswa, contohnya kurang bersemangat dalam mengikuti pembelajaran, kurang kreatif, kurang interaksi dengan lingkungan, dan kurang memiliki sikap empati menggambarkan pudarnya semangat berprestasi dan rasa nasionalisme generasi muda. Hal itu tentunya membahayakan bagi ketahanan negara Indonesia (Sari et al, 2017).

Perkembangan teknologi yang sangat pesat di tengah ketidaksiapan masyarakat menyebabkan beberapa dampak negatif yang timbul (Kristiawan, 2016). Dampak tersebut terlihat di kalangan mahasiswa diantaranya, mirisnya kasus menyontek menggunakan mesin pencari di internet, melakukan copy paste hasil orang lain di internet untuk mengerjakan tugas, dan melakukan replikasi hasil karya penulis lain untuk mengerjakan tugas akhir.

Mahasiswa merupakan generasi muda yang menduduki posisi usia bergejolak, memiliki rasa penasaran yang tinggi, dan mudah menerima pengaruh atau ajakan pada dirinya. Hal ini sejalan dengan adanya kehadiran teknologi yang justru disalahartikan kegunaannya dan membahayakan ketahanan negara Indonesia. Teknologi memang sudah tidak dapat dibendung lagi, saat ini mulai dari balita hingga lanjut usia dapat mengoperasikannya dengan berbagai kepentingan masing-masing. Hanya dengan sebuah genggaman saja, kini seseorang mampu menjelajahi seluruh isi dunia. Oleh karena itu, perilaku open minded telah menguasai jiwa manusia saat ini. Mirisnya untuk bangsa Indonesia, seseorang menjadi mudah terpengaruh oleh berbagai keadaan sehingga menjauhkan dari sifat teguh pendirian.

Keadaan tersebut menjadikan Pancasila menjadi kekuatan utama untuk pencegahan dampak negatif yang terjadi akibat adanya perkembangan teknologi yang terjadi pada generasi muda terkhusus 
mahasiswa. Salah satu wujud peningkatan pemahaman arti penting Pancasila yaitu dengan adanya mata kuliah wajib Pendidikan Pancasila di Perguruan Tinggi. Hal itu sejalan dengan Pasal 35 ayat (3) yang berbunyi tentang ketentuan kurikulum pendidikan tinggi yang wajib memuat mata kuliah agama, Pancasila, kewarganegaraan, dan bahasa Indonesia (Taufiqurrahman, 2018).

Selain itu, pasal 35 ayat (3) Undang-Undang Republik Indonesia Nomor 12 Tahun 2012 tentang Pendidikan Tinggi juga menegaskan bahwa penyelenggaraan pendidikan Pancasila di perguruan tinggi itu wajib sebagai mata kuliah yang berdiri sendiri dan harus dimuat dalam kurikulum masing-masing perguruan tinggi (Taufiqurrahman, 2018).

Mata kuliah pendidikan Pancasila ini biasanya diletakkan di awal semester masuk perkuliahan. Sehingga pemahaman tentang Pancasila nantinya diharapkan mampu dijadikan pegangan mahasiswa untuk aktif dan kritis ketika menghadapi permasalahan yang dihadapi kedepannya. Akan tetapi, masalah yang terjadi yaitu penerapan mata kuliah selama terjadi pandemi ini tidak dapat dilaksanakan secara langsung melainkan hanya secara daring. Sehingga dikhawatirkan mata kuliah pendidikan Pancasila ini tidak sepenuhnya diterima dan dipahami oleh mahasiswa.

Melihat kondisi ini tentunya setiap Perguruan Tinggi tetap mengharapkan mampu melahirkan mahasiswa yang memiliki sifat agent of change, iron stock, moral force, dan guardian of value meskipun pembelajaran dilaksanakan secara daring. Dengan demikian dilakukan penelitian dengan judul "Peran Mata Kuliah Pendidikan Pancasila Secara Daring Terhadap Perilaku Positif Mahasiswa Polbangtan Yogyakarta". Adapun tujuan penelitian ini yaitu untuk mengetahui seberapa berperan mata kuliah pendidikan Pancasila yang dilaksanakan secara daring sehingga mampu menciptakan mahasiswa yang berperilaku positif dalam kehidupan sehari-hari baik di lingkungan keluarga, kampus, ataupun masyarakat.

\section{METODE}

Kegiatan penelitian ini dilaksanakan pada bulan Februari 2021. Metode penelitian yang digunakan adalah deskriptif kuantitaf dimana data akhir ditampilkan dalam bentuk diagram lingkaran. Data tersebut diperoleh melalui dua sumber yaitu 1) sumber primer yaitu hasil kuisioner melalui google form dan 2) sumber sekunder yaitu berbagai literatur yang membahas tentang mempertahankan pemahaman Pancasila pada mahasiswa dan data pendukung lainnya.

Kuisioner yang diberikan berupa pertanyaan singkat mengenai mata kuliah pendidikan Pancasila yang telah dilaksanakan secara daring untuk pertama kalinya di kampus Politeknik Pembangunan Pertanian Yogyakarta. Selain itu, peneliti juga memberikan pertanyaan seputar aspek pemahaman mahasiswa terhadap Pancasila setelah mengikuti proses pembelajaran untuk kemudian diimplementasikan dalam kegiatan sehari-hari. 
Teknik penentuan populasi untuk pengambilan sampel dipilih dengan simple random sampling, berdasarkan data, mahasiswa tingkat 1 Politeknik Pembangunan Pertanian Yogyakarta tahun 2020 berjumlah 136 orang. Teknik penentuan sampel secara purposive yaitu mahasiswa Politeknik Pembangunan Pertanian Yogyakarta semester 1 yang berasal dari program studi Teknologi Benih/ Penyuluhan Pertanian Berkelanjutan/ Agribisnis Hortikultura. Penentuan jumlah sampel menggunakan teknik sampling Proportional Stratified Random Sampling. Melalui teknik tersebut peneliti mengambil sampel mahasiswa dari masing-masing

\section{HASIL DAN PEMBAHASAN}

Di dalam analisis jurnal yang berjudul "Peran Mata Kuliah Pendidikan Pancasila Secara Daring Terhadap Perilaku Positif Mahasiswa Polbangtan Yogyakarta" terdapat 20 mahasiswa yang dilakukan pengisian kuisioner meliputi kegiatan mahasiswa di waktu libur, kreativitas dalam menciptakan karya, tingkat minat belajar, kesan terhadap mata kuliah pendidikan Pancasila secara daring, tingkat literasi mahasiswa, semangat menghadapi tantangan, aktif berorganisasi, bersosialisasi, dan pemahaman terhadap pancasila. Setelah dilakukan pengisian kuisioner oleh para mahasiswa maka diketahui bahwa mata kuliah pendidikan Pancasila yang dilaksanakan secara daring sudah cukup berperan dalam menciptakan mahasiswa yang berperilaku positif dalam kehidupan sehari-hari baik di lingkungan keluarga, kampus, ataupun program studi yang terdapat di Politeknik Pembangunan Pertanian Yogyakarta.

Sampel merupakan populasi dalam bentuk lebih kecil (miniatur population). Besarnya jumlah sampel tergantung pada teknik pengambilan sampel dan jenis penelitiannya. Pada jenis penelitian deskriptif dan teknik sampling Proportional Stratified Random Sampling digunakan 10 $15 \%$ populasi. Berdasarkan beberapa pertimbangan, peneliti mengambil 15\% dari 136 populasi mahasiswa. Melalui perhitungan diperoleh jumlah sampel sebanyak 20 orang.

masyarakat, seperti hasil dan analisis pada diagram lingkaran berikut :

\section{Apakah matkul pendidikan \\ Pancasila itu penting? \\ 20 tanggapan}

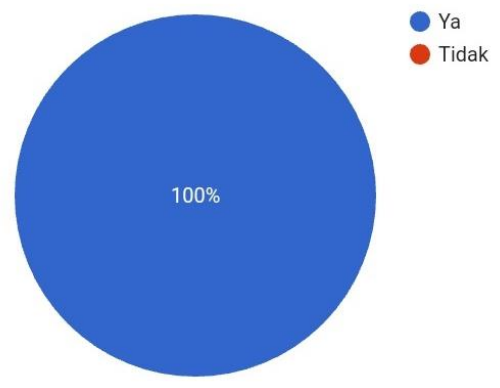

Gambar 1. Diagram hasil jawaban responden 
4. Berkesankah matkul pendidikan

Pancasila yang dilaksanakan selama kuliah daring di semester 1 ini?

20 tanggapan

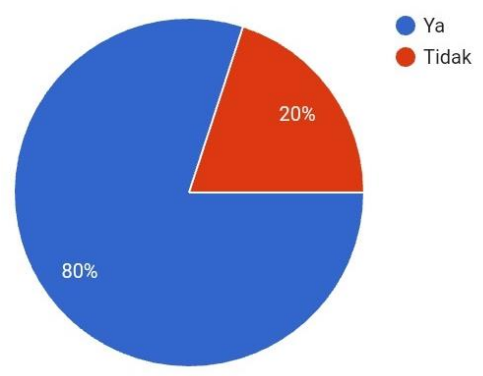

Gambar 2. Diagram hasil jawaban responden

Hasil analisis data dari diagram hasil pengisian kuisioner menunjukkan bahwa $100 \%$ mahasiswa Politeknik Pembangunan Pertanian Yogyakarta semester 1 menyatakan bahwa mata kuliah pendidikan Pancasila itu penting.

Dalam melahirkan mahasiswa yang disiplin dan mampu mengimplementasikan nilai-nilai Pancasila, kampus Politeknik Pembangunan Pertanian Yogyakarta mewajibkan mata kuliah pendidikan Pancasila di semester 1. Mata kuliah pendidikan Pancasila ini diharapkan mampu membuat mahasiswa semakin memahami nilai-nilai yang terkandung dalam sila-sila Pancasila. Sebab Pancasila merupakan dasar negara, ideologi negara, sistem filsafat, dan pandangan hidup bangsa Indonesia. Sehingga melalui pemahaman tersebut diharapkan mahasiswa mampu meletakkan Pancasila pada dirinya untuk kemudian dijadikan pedoman dalam berperilaku positif baik di lingkungan keluarga, pertemanan, maupun masyarakat.
Salah satu faktor pendukung keberhasilan pemahaman mahasiswa tentang Pancasila di kampus Politeknik Pembangunan Pertanian Yogyakarta juga didukung oleh data hasil kuisioner yang diisi oleh 20 responden bahwa $80 \%$ diantaranya menyatakan bahwa mata kuliah pendidikan Pancasila yang dilaksanakan secara daring mampu memberi kesan pada mahasiswa. Artinya, mata kuliah yang tujuannya untuk memberi pemahaman Pancasila kepada mahasiswa ini sudah hampir berhasil.

Meskipun

pembelajaran dilaksanakan secara daring, tetapi mata kuliah Pendidikan Pancasila tidak kehilangan esensi sebagai pencetak generasi muda khususnya mahasiswa yang tidak tercabut dari budaya bangsa Indonesia yang dijadikan identitas negara sekaligus pembeda dengan bangsa yang lain. Pendidikan Pancasila ini nantinya diharapkan mambangun pemahaman generasi muda yang kelak akan terjun langsung di masyarakat, sadar untuk hidup sederhana dan mencintai produk dalam negeri, meningkatkan rasa solidaritas dan persatuan nasional, memahami arti normanorma kehidupan, dan menjadi masyarakat yang sadar hukum.

Hal tersebut sesuai dengan visi mata kuliah Pendidikan Pancasila yaitu terwujudnya kepribadian civitas akademik yang bersumber pada nilai-nilai Pancasila. Sedangkan Misi Pendidikan Pancasila yaitu :

a. Mengembangkan potensi akademik peserta didik (misi psikopedagogis)

b. Menyiapkan peserta didik untuk hidup dan berkehidupan dalam 
masyarakat, bangsa dan negara (misi psikososial).

c. Membangun budaya ber-Pancasila sebagai salah satu determinan kehidupan (misi sosiokultural).

d. Mengkaji dan mengembangkan pendidikan Pancasila sebagai sistem.

(Ristekdikti, 2016)

1. Ketika liburan nanti ...

20 tanggapan

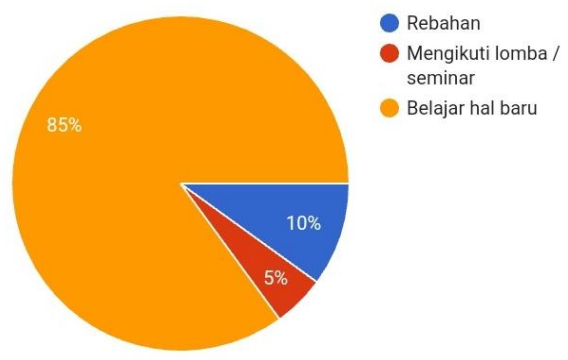

Gambar 3. Diagram hasil jawaban responden

\section{Ketika mengerjakan}

laporan/makalah ...

20 tanggapan

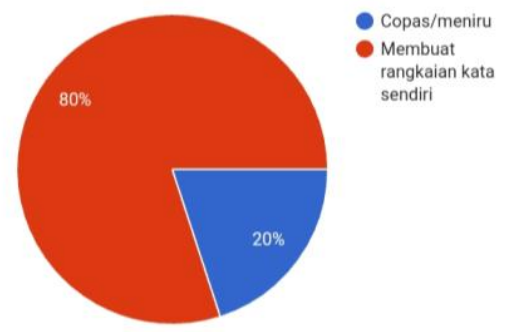

Gambar 4. Diagram hasil jawaban responden
8. Apakah kamu berencana akan aktif berorganisasi?

20 tanggapan

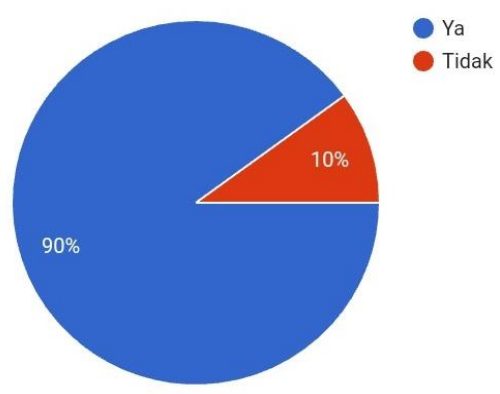

Gambar 5. Diagram hasil jawaban responden

Teknologi dan internet yang berkembang mempermudah penyampaian mata kuliah Pendidikan Pancasila sehingga mampu tersampaikan dengan baik di kampus Politeknik Pembangunan Pertanian Yogyakarta selama pembelajaran daring. Hal tersebut terlihat dari cara mahasiswa memahami dan memaknai nilai-nilai Pancasila yang diperoleh dari mata kuliah untuk kemudian diimplementasikan dalam kehidupan sehari-hari. Seperti perilaku positif yang terlihat pada data hasil pengisian kuisioner di atas bahwa sebagian besar mahasiswa telah mengimplementasikan nilainilai Pancasila dengan perilaku positif seperti memanfaatkan waktu untuk belajar hal baru, tidak memplagiasi karya orang lain, dan berperan aktif dalam organisasi kampus. Perilaku positif tersebut menunjukkan bahwa mahasiswa telah banyak yang paham makna Pancasila saat atau setelah mengikuti mata kuliah Pendidikan Pancasila.

Nilai positif Pancasila memang telah ada sejak masa lampau dan harus ditanamkan pada jiwa 
mahasiswa sebagai generasi muda penerus bangsa. Nilai-nilai Pancasila yang akan selalu sama dan tetap ini untuk dapat mengikuti arus perkembangan zaman ini maka demi terpelihara dari generasi ke generasi diperlukan adanya proses revitalisasi, internalisasi, dan pemeliharaan secara terus-menerus.

Perlunya pendidikan Pancasila diterapkan pada generasi muda yaitu agar Pancasila dan kandungannya tidak dilupakan dengan masuknya era globalisasi yang membuat berbagai macam budaya atau kultur dapat masuk dan memengaruhi adat dan kebiasaan masyarakat Indonesia (Mukhtadi \& Komala, 2018). Ditambah dengan maraknya kontenkonten media sosial yang dapat melunturkan nilai-nilai Pancasila membuat pendidikan Pancasila sangatlah diperlukan bagi generasi muda.

Seperti yang tercantum dalam UU No. 2 Tahun 1989 pasal 1 yang menyatakan bahwa "Pendidikan nasional adalah pendidikan yang berakar pada kebudayaan bangsa Indonesia dan yang berdasarkan pada Pancasila dan Undang-Undang Dasar 1945" (GOI, 1989). Undang-undang tersebut juga didukung oleh penjelasan SK Dirjen Dikti. No.38/DIKTI/Kep/2002 Pasal 3 tentang tujuan pendidikan Pancasila sebagai pengembangan kepribadian di perguruan tinggi (Direktur Jenderal Pendidikan Tinggi Departemen Pendidikan Nasional Republik Indonesia, 2020). Di dalamnya dinyatakan bahwa diadakannya pendidikan Pancasila ini agar mampu mengantarkan mahasiswa memiliki sikap bertanggung jawab, mampu mengenali masalah hidup dan kesejahteraan serta cara pemecahannya, mampu mengenali perubahan dan perkembangan ilmu pengetahuan, teknologi, dan seni, serta mampu memaknai sejarah dan nilai budaya bangsa demi persatuan Indonesia.

\section{SIMPULAN}

Dari hasil analisis disimpulkan bahwa mata kuliah pendidikan Pancasila yang dilaksanakan secara daring di Politeknik Pembangunan Pertanian Yogyakarta sudah mampu terlaksana dengan baik sehingga mahasiswa mampu memahami makna Pancasila serta menciptakan mahasiswa yang berperilaku positif dalam kehidupan sehari-hari baik di lingkungan keluarga, kampus, ataupun masyarakat. Hal tersebut tentunya tidak lepas dari metode pengajaran yang diberikan dosen terhadap mahasiswanya sehingga nilai-nilai Pancasila mampu tersampaikan dengan baik oleh mahasiswa. Pembelajaran yang dilakukan
secara daring ini tentunya memerlukan pikiran yang ekstra untuk mmpu berhasil dalam menyampaikan bahwa Pancasila itu ada dan harus mampu menjadi pedoman dalam setiap tindakan yang dilakukan oleh mahasiswa.

Perilaku positif mahasiswa saat atau setelah mengikuti mata kuliah pendidikan Pancasila diantaranya yaitu memanfaatkan waktu untuk belajar hal baru, tidak memplagiasi karya orang lain, dan berperan aktif dalam organisasi kampus. 


\section{DAFTAR PUSTAKA}

Direktur Jenderal Pendidikan Tinggi Departemen Pendidikan Nasional Republik Indonesia. (2020). Rambu-Rambu Pelaksanaan Mata Kuliah Pengembangan Kepribadian di Perguruan Tinggi. Diakses 5 Maret 2021, diakses dari https://jdih.kemenkeu.go.id/fullte xt/1989/2TAHUN 1989.

GOI. (1989). Undang-Undang Republik Indonesia Nomor 2 Tahun 1989 Tentang Sistem Pendidikan Nasional. Diakses 5 Maret 2021, diakses dari https://luk.staff.ugm.ac.id/atur/U U2-1989Sisdiknas.pdf

Kristiawan, M. (2016). Telaah Revolusi Mental dan Pendidikan Karakter Dalam Pembentukan Sumber Daya Manusia Indonesia Yag Pandai dan Berakhlak Mulia. Jurnal Ta'dib, 18(1). pp. 13-25

Mukhtadi \& R. Madha Komala. (2018). Membangun Kesadaran Bela Negara Bagi Generasi Milenial Dalam Sistem Pertahanan Negara. Jurnal Manajemen Pertahanan, 4(2). pp. 64-83

Ristekdikti. (2016). Visi dan Misi Mata Kuliah Pendidikan Pancasila. Diakses 6 Februari 2020. diakses dari

https://www.google.com/amp/s/ malvaspalette.wordpress.com/20 17/09/29/visi-dan-misi-matakuliah-pendidikanpancasila/amp/

Sari, Wiwin Anggita \& Bukman Lian. (2017). Menjadikan Mata Kuliah Pendidikan Pancasila sebagai Media Penanaman Nilai-Nilai Bela Negara. Jurnal Manajemen, Kepemimpinan, dan Supervisi Pendidikan, 1(1). pp. 303-314

Taufiqurrahman. (2018). Pendidikan Pancasila, Jakarta: Direktorat Jenderal Pembelajaran dan Kemahasiswaan Kementerian Riset Teknologi dan Pendidikan Tinggi.

\section{UCAPAN TERIMA KASIH}

Ucapan terima kasih kami ucapkan kepada semua pihak, responden yaitu mahasiswa tingkat 1 Kampus Politeknik Pembangunan Pertanian Yogyakarta, dosen Pengampu mata kuliah Pendidikan Pancasila bapak Hastangka, rekanrekan, dan semua penulis yang tercantum dalam literatur yang telah membantu memberikan bantuan sehingga kami dapat menyelesaikan jurnal ini. 